Article

\title{
Photoelectric Properties of Si Doping Superlattice Structure on $6 \mathrm{H}-\mathrm{SiC}(0001)$
}

\author{
Lianbi Li ${ }^{1, *,+}$, Yuan Zang ${ }^{2,+}$, Jichao $\mathrm{Hu}^{2,+}$, Shenghuang Lin $^{3}$ and Zhiming Chen ${ }^{2}$ \\ 1 School of Science, Xi'an Polytechnic University, Xi'an 710048, China \\ 2 Department of Electronic Engineering, Xi'an University of Technology, Xi'an 710048, China; \\ zangyuan82@163.com (Y.Z.); hujichao0613@163.com (J.H.); chenzm@xaut.edu.cn (Z.C.) \\ 3 Department of Applied Physics, The Hong Kong Polytechnic University, Hong Kong, China; \\ shenghuang.lin@polyu.edu.hk \\ * Correspondence: xpu_lilianbi@163.com; Tel.: +86-029-8233-0277 \\ + These authors contributed equally to this work. \\ Academic Editor: Der-Jang Liaw \\ Received: 15 March 2017; Accepted: 19 May 2017; Published: 25 May 2017
}

\begin{abstract}
The energy-band structure and visible photoelectric properties of a $\mathrm{p} / \mathrm{n}$-Si doping superlattice structure (DSL) on $6 \mathrm{H}-\mathrm{SiC}$ were simulated by Silvaco-TCAD. The, $\mathrm{n}$ the Si-DSL structures with $40 \mathrm{~nm}-\mathrm{p}-\mathrm{Si} / 50 \mathrm{~nm}-\mathrm{n}-\mathrm{Si}$ multilayers were successfully prepared on $6 \mathrm{H}-\mathrm{SiC}(0001) \mathrm{Si}$-face by chemical vapor deposition. TEM characterizations of the $\mathrm{p} / \mathrm{n}$-Si DSL confirmed the epitaxial growth of the Si films with preferred orientation and the misfit dislocations with a Burgers vector of $1 / 3$ $<21-1>$ at the $\mathrm{p}-\mathrm{Si} / \mathrm{n}-\mathrm{Si}$ interface. The device had an obvious rectifying behavior, and the turn-on voltage was about $1.2 \mathrm{~V}$. Under the visible illumination of $0.6 \mathrm{~W} / \mathrm{cm}^{2}$, the device demonstrated a significant photoelectric response with a photocurrent density of $2.1 \mathrm{~mA} / \mathrm{cm}^{2}$. Visible light operation of the Si-DSL/6H-SiC heterostructure was realized for the first time.
\end{abstract}

Keywords: $\mathrm{Si} / 6 \mathrm{H}-\mathrm{SiC}$ heterostructure; doping superlattice; photoelectric properties; chemical vapor deposition; transmission electron microscopy

\section{Introduction}

$\mathrm{SiC}$ is a desirable material for power devices due to its superior physical properties such as a wide bandgap, high thermal conductivity, and high critical electric field, etc. [1-7]. In order to realize the visible light operation of $\mathrm{SiC}$ photoelectric devices applied in high temperature and high power regions, $\mathrm{Si}$ films were grown on $\mathrm{SiC}$ for visible light absorption [8,9]. The SiC-based $\mathrm{Si} / \mathrm{SiC}$ heterojunction is comparatively less studied [10-13]. Present studies mainly focus on using an $\mathrm{Si}$ inter-layer to reduce the interface states density of the $\mathrm{SiC}$ surface oxide layer in SiC MOSFET [12,13], and seldom focus on the aspects of light operation of SiC photoelectric devices. In our previous work, visible-light-operated $\mathrm{Si} / \mathrm{SiC}$ photodiodes with PIN and Schottky structures were prepared for the first time [8,9]. However, because of the large lattice mismatch between $\mathrm{Si}$ and $6 \mathrm{H}-\mathrm{SiC}(\sim 19.6 \%)$, there was still a high density of structural defects such as edge misfit dislocations at the hetero-interface [14], stacking faults, and twins in Si films [15], which led to a small carrier lifetime and poor device properties [8,9]. Interestingly, the doping superlattice (DSL) is a structure composed of periodic $\mathrm{p} / \mathrm{n}$ doped layers, in which the space-charge potential of ionized impurities modulates the bandgaps of the materials, and hence separates the electrons and holes spatially and further enhances the carrier lifetime and the photoelectric properties of the device [16-19]. Employing DSL structures based on amorphous hydrogenated silicon (a-Si:H) [16,17], an increase in the photoconductivity up to tenfold can be observed when compared to that of the unstructured a-Si:H, which paves a possible 
way for the fabrication of DSL structures on SiC substrates to improve the photoconductivity of SiC-based photodetectors.

In this paper, $\mathrm{p} / \mathrm{n}-\mathrm{Si}$ DSL structures on $6 \mathrm{H}-\mathrm{SiC}$ substrates were accordingly adopted to promote the photoelectric properties of the $\mathrm{Si} / \mathrm{SiC}$ heterojunctions. The energy-band structure and visible photoelectric properties of the $\mathrm{p} / \mathrm{n}$-Si DSL structures on $6 \mathrm{H}-\mathrm{SiC}$ were simulated by Silvaco-TCAD. Then, the visible photodetector with the $\mathrm{p} / \mathrm{n}$-Si DSL structure was prepared on $6 \mathrm{H}-\mathrm{SiC}(0001)$ Si-face by low-pressure chemical vapor deposition (LPCVD). Transmission electron microscopy (TEM) and selected area electron diffraction (SAED) were employed to investigate the interface structure of the $\mathrm{Si}-\mathrm{DSL} / \mathrm{SiC}$ heterostructure, and its photoelectric properties were investigated.

\section{Results and Discussion}

\subsection{Device Structure and the Simulation Results}

Figure 1a shows the schematic diagram of $\mathrm{p} / \mathrm{n}-\mathrm{Si}$ DSL and PIN-Si structures on $6 \mathrm{H}-\mathrm{SiC}$. Because of the wide bandgap $6 \mathrm{H}-\mathrm{SiC}$ is used as the penetration window of the visible lights in photoelectric characterization. The visible light passes through $6 \mathrm{H}-\mathrm{SiC}$ freely and is absorbed in the $\mathrm{p} / \mathrm{n}-\mathrm{Si}$ DSL structures. The photoelectric properties of the $\mathrm{p} / \mathrm{n}-\mathrm{Si}$ DSL structure on $6 \mathrm{H}-\mathrm{SiC}$ are simulated by Silvaco-TCAD. In simulation the electron affinity and bandgap of $6 \mathrm{H}-\mathrm{SiC}$ are set as $3.85 \mathrm{eV}$ and $3.0 \mathrm{eV}$ [20], respectively. The impurity concentrations of the n-Si and p-Si layers are set as $10^{15} \mathrm{~cm}^{-3}$ and $10^{16} \mathrm{~cm}^{-3}$. The impurity concentration of the n-type $6 \mathrm{H}-\mathrm{SiC}$ with a thickness of $300 \mu \mathrm{m}$ is $10^{17} \mathrm{~cm}^{-3}$, which is consistent with the experimental parameters. Figure $1 \mathrm{~b}$ shows the energy-band diagram of $\mathrm{p} / \mathrm{n}$-Si DSL structures on $6 \mathrm{H}-\mathrm{SiC}$ in a thermal equilibrium state. It is shown that there are energy offsets of the n-type isotype $\mathrm{Si} / 6 \mathrm{H}-\mathrm{SiC}$ heterostructure in the conduction band $\Delta \mathrm{E}_{\mathrm{C}}$ and valance band $\Delta \mathrm{E}_{\mathrm{V}}$, which are about $0.21 \mathrm{eV}$ and $1.65 \mathrm{eV}$, respectively. The electron barrier of the $\mathrm{Si} / 6 \mathrm{H}-\mathrm{SiC}$ heterostructure is much lower than the hole barrier, and thus the electrons dominate the current carriers.

(a)
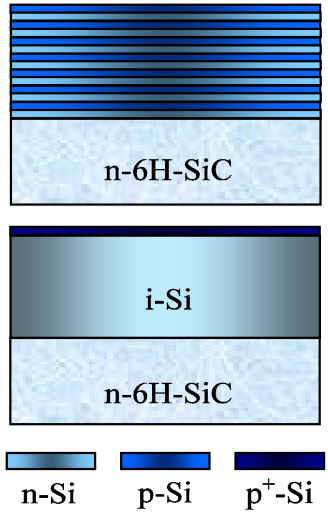

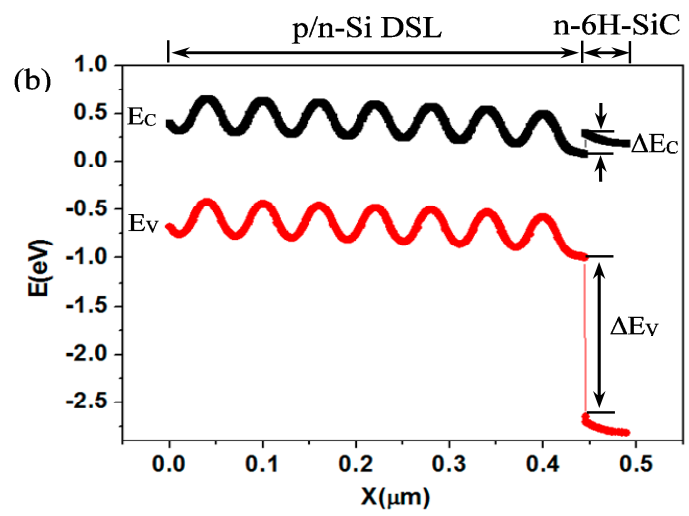

Figure 1. Schematic diagram of $\mathrm{p} / \mathrm{n}$-Si DSL and PIN-Si structures on $6 \mathrm{H}-\mathrm{SiC}(\mathbf{a})$; energy-band diagram of $\mathrm{p} / \mathrm{n}$-Si DSL structure with seven $\mathrm{p} / \mathrm{n}-\mathrm{Si}$ junctions on $6 \mathrm{H}-\mathrm{SiC}$ in a thermal equilibrium state $(\mathbf{b})$. $\Delta \mathrm{E}_{\mathrm{C}}=0.21 \mathrm{eV}, \Delta \mathrm{E}_{\mathrm{V}}=1.65 \mathrm{eV}$.

Figure 2a shows the simulated photoelectric properties of the Si-DSL/6H-SiC heterostructure with different impurity concentrations and thicknesses. With the decrease of the $\mathrm{p} / \mathrm{n}-\mathrm{Si}$ impurity concentration the photocurrent density JSC increases. This is due to the widen space-charge region, which leads to the low recombination of the photogenerated carriers. In particular, the impurity concentration of the p-Si layer has an important influence on the photoelectric properties, as shown in Figure 2b. As the impurity concentration of the p-layer decreases, the JSC increases rapidly, and the turn-on voltage $\mathrm{V}_{\mathrm{OC}}$ decreases correspondingly. Compared with the impurity concentration, the thickness has a relatively weak influence on the photoelectric properties. It is shown that the 
photocurrent density increases slightly and then declines as the thickness increases. Under a visible illumination of $0.1 \mathrm{~W} / \mathrm{cm}^{2}$, ISC reaches the largest value as the impurity concentrations are $10^{15} \mathrm{~cm}^{-3}$ and $10^{16} \mathrm{~cm}^{-3}$, while the thickness of the n-layer and p-layer are $50 \mathrm{~nm}$ and $40 \mathrm{~nm}$, respectively.
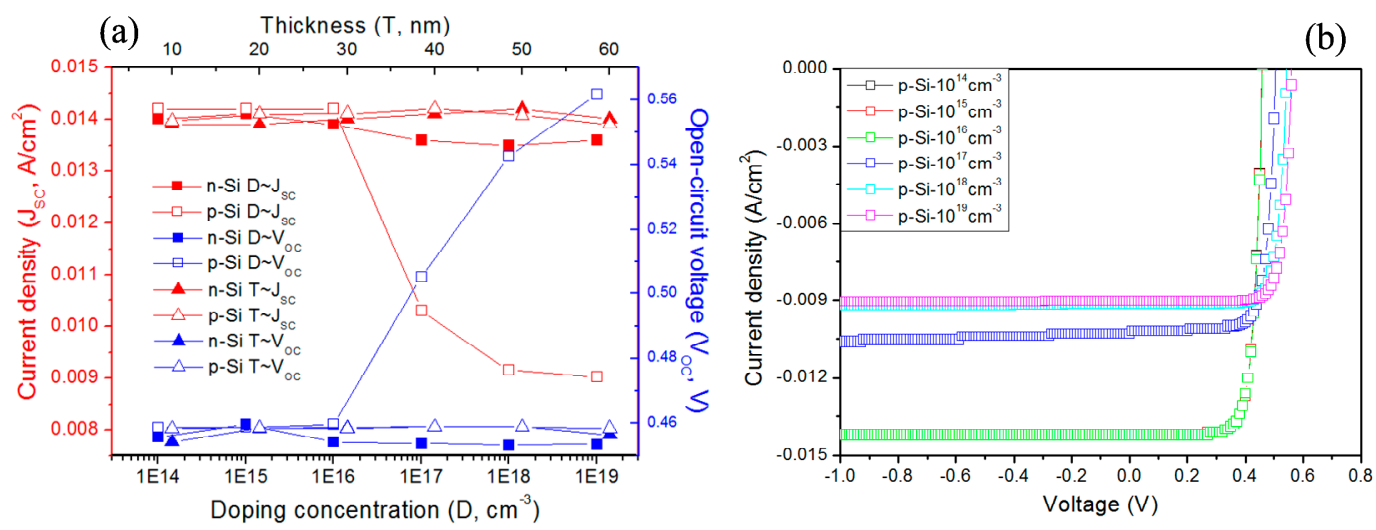

Figure 2. Simulated $\mathrm{J}_{\mathrm{SC}}$ and $\mathrm{V}_{\mathrm{OC}}$ of the $\mathrm{p} / \mathrm{n}-\mathrm{Si}$ DSL structure on $6 \mathrm{H}-\mathrm{SiC}$ with different impurity concentrations and thicknesses under a visible illumination of $0.1 \mathrm{~W} / \mathrm{cm}^{2}$ (a); J-V curves of the $\mathrm{Si}-\mathrm{DSL} / 6 \mathrm{H}-\mathrm{SiC}$ heterostructure with different impurity concentrations of the $\mathrm{p}$-Si layer $(\mathbf{b})$.

The photoelectric properties of the optimized Si-DSL/6H-SiC heterostructure are compared with the PIN Si $/ 6 \mathrm{H}-\mathrm{SiC}$ heterostructure. When the impurity concentrations of the n-layer and p-layer are $10^{15} \mathrm{~cm}^{-3}$ and $10^{16} \mathrm{~cm}^{-3}$, the ISC of the DSL structure is $3.0 \%$ higher than that of the PIN Si/ $6 \mathrm{H}-\mathrm{SiC}$ heterostructure under a visible illumination of $0.1 \mathrm{~W} / \mathrm{cm}^{2}$, as shown in Figure 3 . It is demonstrated that the Si-DSL/6H-SiC heterostructure has more advantages than the PIN Si/6H-SiC structure in the photoelectric response, especially in the case of small carrier lifetime. Furthermore, the PIN Si/6H-SiC heterostructure has the higher $\mathrm{V}_{\mathrm{OC}}$. This is due to the high impurity concentration of the p-Si layer, which results in a higher electron barrier.

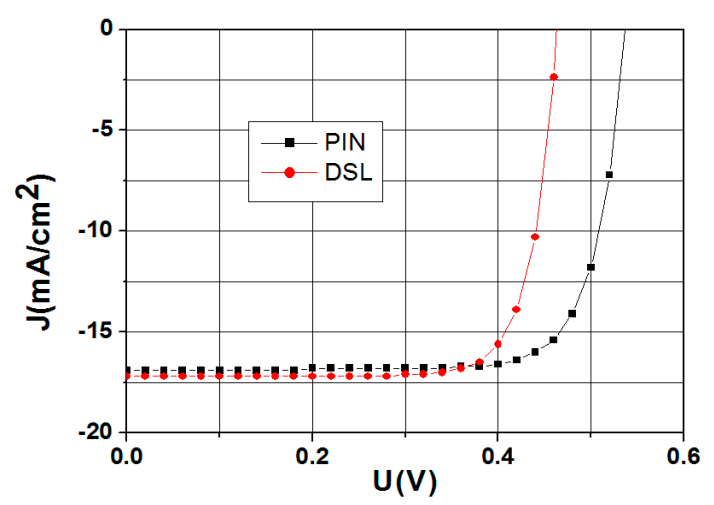

Figure 3. Simulated J-V curves of Si-DSL/6H-SiC heterostructure and PIN Si/6H-SiC heterostructure under a visible illumination of $0.1 \mathrm{~W} / \mathrm{cm}^{2}$.

\subsection{Experiments and Results Discussion}

The $\mathrm{p} / \mathrm{n}$-Si DSL structures are grown on n-type 6H-SiC(0001) Si-face by LPCVD. An n-type doped (impurity concentration of $\sim 10^{17} \mathrm{~cm}^{-3}$ ) $6 \mathrm{H}-\mathrm{SiC}(0001)$ wafer with a thickness of $300 \mu \mathrm{m}$ was purchased from II-VI Inc. (Saxonburg, PA, USA). Silane $\left(\mathrm{SiH}_{4}\right)$, diborane $\left(\mathrm{B}_{2} \mathrm{H}_{6}\right)$, and hydrogen $\left(\mathrm{H}_{2}\right)$ are used as a silicon source, a p-type doping source, and a carrier, respectively. After the standard Radio Corporation of America (RCA) cleaning processes, $6 \mathrm{H}-\mathrm{SiC}$ substrates were treated in high-purity $\mathrm{H}_{2}$ at $1050{ }^{\circ} \mathrm{C}$ for $10 \mathrm{~min}$. Then, the $\mathrm{p} / \mathrm{n}$-Si DSL structures with seven $\mathrm{p} / \mathrm{n}$-Si junctions were prepared at $900{ }^{\circ} \mathrm{C}$. 
To prepare the ohmic contacts, $\mathrm{Al}$ electrodes on $\mathrm{Si}$ and $\mathrm{Ni}$ electrodes on $6 \mathrm{H}-\mathrm{SiC}$ were prepared by magnetron sputtering followed by annealing at $900{ }^{\circ} \mathrm{C}$ and $1050{ }^{\circ} \mathrm{C}$, respectively.

The low magnification cross-sectional TEM bright-field image of the Si-DSL/6H-SiC heterostructure is shown in Figure 4a. The $\mathrm{p} / \mathrm{n}$-Si DSL structures with obvious contrast differences show $40 \mathrm{~nm}-\mathrm{p}-\mathrm{Si} / 50 \mathrm{~nm}-\mathrm{n}-\mathrm{Si}$ multilayers on $6 \mathrm{H}-\mathrm{SiC}(0001)$. The $\mathrm{p}-\mathrm{Si} / \mathrm{n}-\mathrm{Si}$ interface is abrupt in structure, and the $\mathrm{p}$-Si layers exhibit brighter contrast. The SAED patterns of the $\mathrm{p} / \mathrm{n}$-Si DSL corresponding to the $\mathrm{Si}[011]$ zone axes confirm the epitaxial growth of the Si films with [1-11] preferred orientation, as shown in Figure 4b. Figure 4c shows a high-resolution TEM image of the p-Si/n-Si interface. There are some structural defects at the interface. The Si[111] orientation was tilted by $0.5^{\circ}$ at the interface. Fourier filtering technique (FFT) is applied to reveal the periodic atomic arrangement of the $\mathrm{p}-\mathrm{Si} / \mathrm{n}-\mathrm{Si}$ interface. Figure $4 \mathrm{~d}$ shows the enlarged FFT image of region 1 . Relatively small amounts of misfit dislocations (MD) are observed at the $\mathrm{p}-\mathrm{Si} / \mathrm{n}-\mathrm{Si}$ interface, which can be easily identified by extra lattice fringes in the p-Si layer. The MDs are of the pure edge type with a Burgers vector of $1 / 3<21-1>$ parallel to the interface, and are labelled in Figure 4d. Moreover, the crystal plane spacing of the Si film has relatively obvious change at the $\mathrm{p}-\mathrm{Si} / \mathrm{n}-\mathrm{Si}$ interface, as shown in Figure 4e. The crystal plane spacing of $\mathrm{p}-\mathrm{Si}$ is $0.64 \%$ lower than the $\mathrm{n}-\mathrm{Si}$ layer. This demonstrates that the occurrence of the interfacial MDs cannot accommodate most of lattice mismatch strain and cause the lattice to change at the $\mathrm{p} / \mathrm{n}-\mathrm{Si}$ DSL interface.
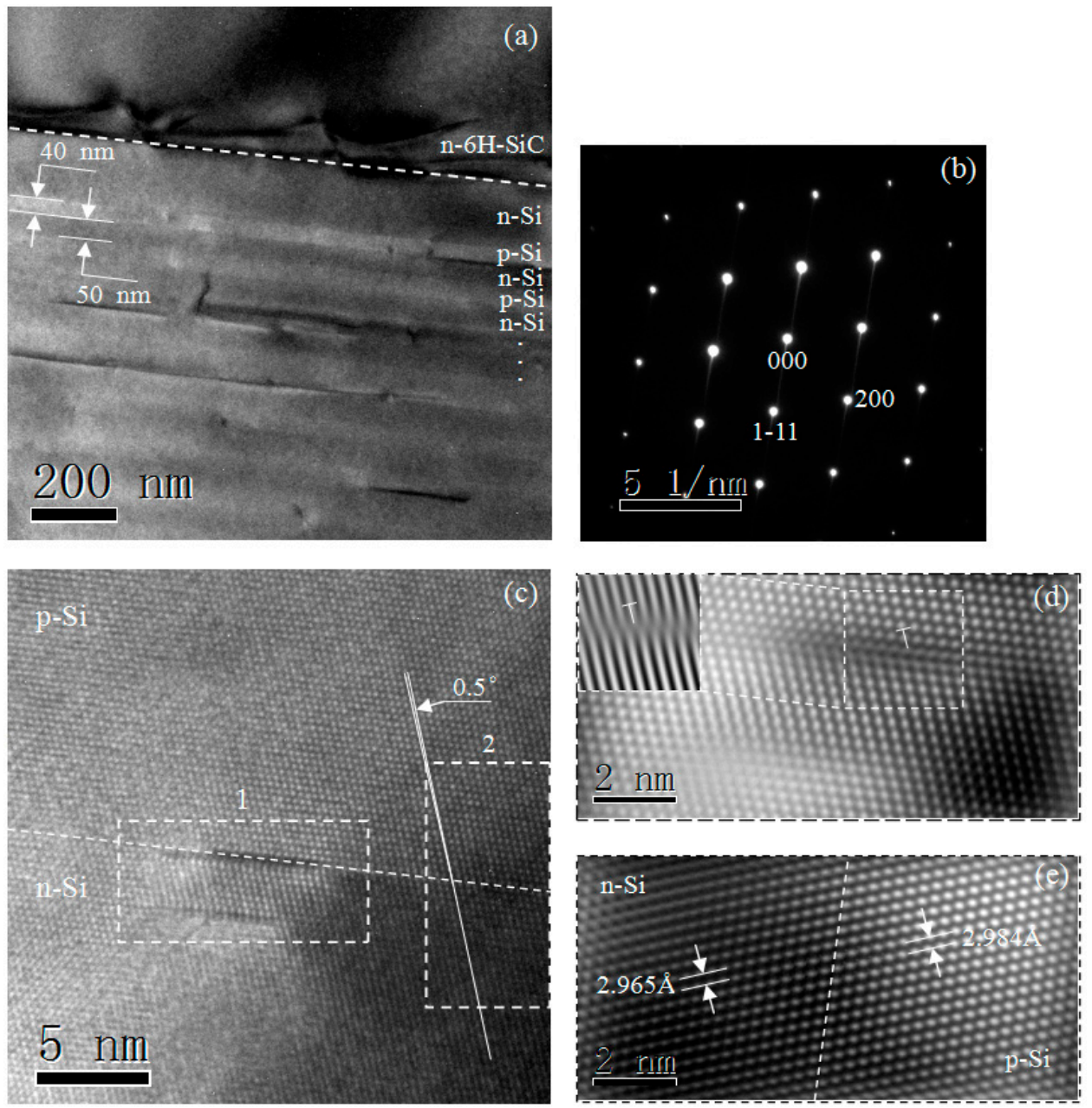

Figure 4. TEM and selected area electron diffraction (SAED) images of the Si-DSL structures with seven $\mathrm{p} / \mathrm{n}$-Si junctions on 6H-SiC. (a) Cross-sectional low magnification TEM image; (b) SAED patterns of the Si films; (c) HRTEM image of the p-Si/n-Si interface; and the processed HRTEM images of region 1 (d) and region 2 (e) by using the Fourier filtering technique. 
Figure 5 presents the photoelectric properties of the Si-DSL/6H-SiC heterostructure. The heterostructure has obvious rectifying characteristics with a rectifying ratio up to 40 at $\pm 5 \mathrm{~V}$, and the turn-on voltage is about $1.2 \mathrm{~V}$, as shown in the inset. Under a visible illumination of $0.6 \mathrm{~W} / \mathrm{cm}^{2}$, the heterostructure demonstrates apparent photoelectric behavior with a JSC of $\sim 2.1 \mathrm{~mA} / \mathrm{cm}^{2}$. Visible light operation of the Si-DSL/6H-SiC heterostructure is realized. However, compared with the simulated results, the device demonstrates a smaller JSC and a large reverse leakage current. When the reverse voltage is $5 \mathrm{~V}$, the leakage current density is as large as $0.36 \mathrm{~A} / \mathrm{cm}^{2}$. This is due to the structural defects such as the MDs at the $\mathrm{p}-\mathrm{Si} / \mathrm{n}$-Si interface, which result in large recombination current and deteriorating device properties.

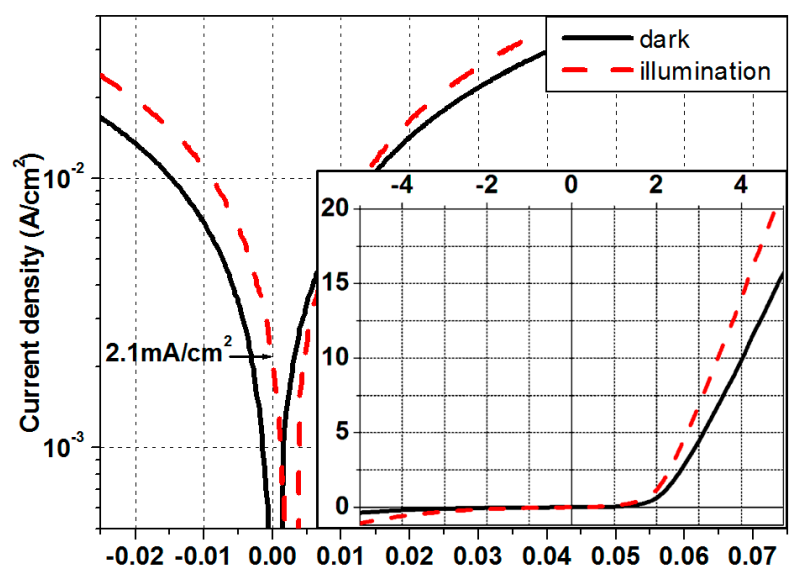

Figure 5. Photoelectric properties of the $\mathrm{p} / \mathrm{n}-\mathrm{Si}$ DSL structures with seven $\mathrm{p} / \mathrm{n}-\mathrm{Si}$ junctions on $6 \mathrm{H}-\mathrm{SiC}$.

\section{Conclusions}

In this paper, the energy-band structure and visible photoelectric properties of an Si-DSL doping superlattice structure on $6 \mathrm{H}-\mathrm{SiC}$ were simulated by Silvaco-TCAD. The Si-DSL structures with $40 \mathrm{~nm}-\mathrm{p}-\mathrm{Si} / 50 \mathrm{~nm}-\mathrm{n}-\mathrm{Si}$ multilayers were successfully prepared on 6H-SiC(0001) Si-face by LPCVD. The energy offsets of the $\mathrm{n}-\mathrm{Si} / \mathrm{n}-6 \mathrm{H}-\mathrm{SiC}$ heterojunction in the conduction band and valance band were calculated to be $0.21 \mathrm{eV}$ and $1.65 \mathrm{eV}$, respectively. The electrons dominate the current carriers because of the low electron barrier. TEM characterizations of the $p / n-S i$ DSL confirmed the epitaxial growth of the Si films with [1-11] preferred orientation and the misfit dislocations with a Burgers vector of $1 / 3<21-1>$ at the $\mathrm{p}$-Si/n-Si interface. Under a visible illumination of $0.6 \mathrm{~W} / \mathrm{cm}^{2}$, the heterostructure demonstrates apparent rectifying behavior and significant photoelectric response with a photocurrent density of $2.1 \mathrm{~mA} / \mathrm{cm}^{2}$. Visible light operation of the Si-DSL/6H-SiC heterostructure was successfully realized.

Acknowledgments: This work was supported financially by the National Natural Science Foundation of China (Grant No. 51402230, 21503153), the Natural Science Basic Research Plan in Shaanxi Province of China (Grant No. 2015JM6282, 2016JM1018), the Science and Technology Star Project of Shaanxi Province (Grant No. 2016KJXX-45), the Scientific Research Program Funded by Shaanxi Provincial Education Department (Grant No. 14JK1302, 16JK1319, 16JK1335), and the China Postdoctoral Science Foundation (Grant No. 2013M532072).

Author Contributions: L.B. Li and Z.M. Chen conceived and designed the experiments. Y. Zang and J.C. Hu prepared the DSL-Si/SiC heterostructures. S.H. Lin performed TEM measurements.

Conflicts of Interest: The authors declare no conflicts of interest.

\section{References}

1. Seely, J.F.; Kjornrattanawanich, B.; Holland, G.E.; Korde, R. Response of a SiC photodiode to extreme ultraviolet through visible radiation. Opt. Lett. 2005, 30, 3120-3122. [CrossRef] [PubMed] 
2. Hu, J.; Xin, X.; Zhao, J.H.; Yan, F.; Guan, B.; Seely, J.; Kjornrattanawanich, B. Highly sensitive visible-blind extreme ultraviolet $\mathrm{Ni} / 4 \mathrm{H}-\mathrm{SiC}$ Schottky photodiodes with large detection area. Opt. Lett. 2006, 31, 1591-1593. [CrossRef] [PubMed]

3. Lin, S.H.; Chen, Z.M.; Liu, B.; Li, L.B.; Feng, X.F. Identification and control of SiC polytypes in PVT method. J. Mater. Sci. Mater. Electron. 2010, 21, 326-330. [CrossRef]

4. Liu, W.T.; Chen, Z.M. Feasibility of the light-activation in 4H-SiC thyristors. Power Electron. 2011, 45, 89-91. [CrossRef]

5. Lin, S.H.; Chen, Z.M.; Liang, P.; Ba, Y.T.; Liu, S.J. Formation and suppression of misoriented grains in $6 \mathrm{H}-\mathrm{SiC}$ crystals. CrystEngComm 2011, 13, 2709-2713. [CrossRef]

6. Lin, S.H.; Chen, Z.M.; Li, L.B.; Yang, C. Effect of impurities on the Raman scattering of $6 \mathrm{H}-\mathrm{SiC}$ crystals. Mater. Res. 2012, 15, 833-836. [CrossRef]

7. $\quad$ Lin, S.H.; Chen, Z.M.; Yang, Y.; Liu, S.J.; Ba, Y.T.; Li, L.B.; Yang, C. Formation and evolution of micropipes in $\mathrm{SiC}$ crystals. CrystEngComm 2012, 14, 1588-1594. [CrossRef]

8. Li, L.B.; Chen, Z.M.; Ren, Z.Q.; Gao, Z.J. Non-UV Photoelectric Properties of the Ni/n-Si/N ${ }^{+}-S i C$ Isotype Heterostructure Schottky Barrier Photodiode. Chin. Phys. Lett. 2013, 30, 097304. [CrossRef]

9. Li, L.B.; Chen, Z.M.; Liu, W.T.; Li, W.C. Electrical and photoelectric properties of p-Si $/ \mathrm{n}^{+}-6 \mathrm{H}-\mathrm{SiC}$ heterojunction non-ultraviolet photodiode. Electron. Lett. 2012, 48, 1227-1228. [CrossRef]

10. Zang, Y.; Li, L.B.; An, J.; Huang, L.; Jin, H.L. Si/SiC heterojunction prepared by metal induced crystallization of amorphous silicon. Mater. Lett. 2017, 188, 409-412. [CrossRef]

11. Pérez-Tomás, A.; Jennings, M.R.; Davis, M.; Covington, J.A.; Mawby, P.A.; Shah, V.; Grasby, T. Characterization and Modeling of n-n Si/SiC Heterojunction Diodes. J. Appl. Phys. 2007, 102, 014505. [CrossRef]

12. Pérez-Tomás, A.; Jennings, M.R.; Davis, M.; Shah, V.; Grasby, T.; Covington, J.A.; Mawby, P.A. High doped MBE Si p-n and n-n heterojunction diodes on 4H-SiC. Microelectron. J. 2007, 38, 1233-1237. [CrossRef]

13. Guy, O.J.; Jenkins, T.E.; Lodzinski, M.; Castaing, A.; Wilks, S.P.; Bailey, P.; Noakes, T.C.Q. Ellipsometric and MEIS Studies of $4 \mathrm{H}-\mathrm{SiC} / \mathrm{Si} / \mathrm{SiO}_{2}$ and $4 \mathrm{H}-\mathrm{SiC} / \mathrm{SiO}_{2}$ Interfaces for MOS Devices. Mater. Sci. Forum 2007, 556, 509-512. [CrossRef]

14. Li, L.B.; Chen, Z.M.; Zang, Y.; Feng, S. Atomic-scale characterization of Si(110)/6H-SiC(0001) heterostructure by HRTEM. Mater. Lett. 2016, 163, 47-50. [CrossRef]

15. Li, L.B.; Chen, Z.M.; Zang, Y. Epitaxial growth of Si/SiC heterostructures withdifferent preferred orientations on $6 \mathrm{H}-\mathrm{SiC}(0001)$ by LPCVD. CrystEngComm 2016, 18, 5681-5685. [CrossRef]

16. Kakalios, J.; Fritzsche, H. Persistent photoconductivity in doping-modulated amorphous semiconductors. Phys. Rev. Lett. 1984, 53, 1602. [CrossRef]

17. Hundhausen, M.; Ley, L.; Carius, R. Carrier recombination times in amorphous-silicon doping superlattices. Phys. Rev. Lett. 1984, 53, 1598. [CrossRef]

18. Yang, S.Y.; Seidel, J.; Byrnes, S.J.; Shafer, P.; Yang, C.-H.; Rossell, M.D.; Yu, P.; Chu, Y.-H.; Scott, J.W.; Ager, L.W.; et al. Above-bandgap voltages from ferroelectric photovoltaic devices. Nat. Nanotechnol. 2010, 5, 143-147. [CrossRef] [PubMed]

19. Sandomirski, V.B.; Khalilov, S.S.; Chensky, E.V. The anomalous photovoltage in a model of the highly doped and compensated ferroelectric semiconductor. Ferroelectrics 1982, 43, 147-151. [CrossRef]

20. Teraji, T.; Hara, S. Control of interface states at metal/6H-SiC(0001) interfaces. Phys. Rev. B 2004, 70, 035312. [CrossRef]

(C) 2017 by the authors. Licensee MDPI, Basel, Switzerland. This article is an open access article distributed under the terms and conditions of the Creative Commons Attribution (CC BY) license (http:/ / creativecommons.org/licenses/by/4.0/). 